\title{
A INSERÇÃO ACELERADA DAS TDIC NA EDUCAÇÃO INFANTIL E ENSINO FUNDAMENTAL I DIANTE A PANDEMIA DA COVID - 19
}

\author{
DTIC'S sudden insertion in childhood education and elementary education before the \\ Covid-19 pandemic
}

La inserción acelerada del TDIC en la educación infantil y educación fundamental I antes de la pandemia de Covid-19

Received: october/2020

Accepted: december $/ 2020$

Available online: december $/ 2020$

Lucilene Simone Felippe Oliveira, Graduada em Pedagogia; Especialização em Planejamento

Educacional e Docência do Ensino Superior, Brasil. E-mail: lucilene.felippe@gmail.com

\begin{abstract}
Resumo: Tratando-se de paradigmas educacionais, os que incluem as Tecnologias Digitais de Informação e Comunicação - TDIC são de grande relevância, especialmente diante do cenário atual, pois observa-se a importância e necessidade da inserção dessas tecnologias ao dia a dia das escolas no processo de ensino e aprendizagem. Porém, uma questão relacionada à saúde mundial, o novo coronavírus, impôs o uso dessas ferramentas de maneira abrupta e com pouco planejamento. Assim, estudantes de toda a educação básica, bem como professores, coordenadores, gestores e toda a equipe pedagógica, precisaram, repentinamente, familiarizar-se com o uso das plataformas digitais de aprendizagem e suas ferramentas. Levando tais afirmações em consideração, surgiram os seguintes questionamentos: Frente a conjuntura educacional imposta pela pandemia, será que o modelo de educação (online) conseguiu englobar a maioria das crianças da Educação Infantil, principalmente as crianças da pré-escola (4 e 5 anos) e do Ensino Fundamental I ( $1^{\circ}$ ao $5^{\circ}$ ano), em especial as advindas de instituições públicas e menos favorecidas? Será que houve qualidade no processo de ensino e aprendizagem com esse novo modelo de educação? Portanto, a pesquisa consiste em exploração bibliográfica de abordagem qualitativa. Os dados foram coletados a partir de leituras realizadas em obras publicadas, artigos científicos disponíveis na internet, congressos e palestras virtuais.
\end{abstract}

RBPPD/BRJPD | Vol. 2 | n. 4 | p. 95 -117, 2020. 
Palavras-chave: TDIC, Educação, Pandemia, Educação Infantil, Ensino Fundamental I.

\begin{abstract}
When we discuss education paradigms, those that include Digital Information and Communication Technologies - DICT are of great relevance, given the importance and necessity of the insertion of these technologies in the daily routine of schools, in the teaching and learning processes. However, an issue related to global health, the new coronavirus, imposed the use of these tools abruptly and with little planning. Thus basic education students, as well as teachers, coordinators, managers, and the entire pedagogical team, suddenly needed to become familiar with the use of digital learning platforms and their tools. Taking this into consideration, the following questions emerged: Given the educational situation imposed by the pandemic, will the education model (online) be able to encompass the majority of children in Early Childhood Education, especially preschoolers ( 4 and 5 years old) and Elementary School (1st to 5th grade), especially those from public and less favored institutions? What is the quality of the teaching and learning process in this new model of education? Therefore, this paper aims to present a bibliographic research on the topic carried out from a qualitative approach. The data were collected from readings in published scientific articles available on the internet, congresses, and virtual lectures.
\end{abstract}

Keywords: Digital Information and Communication Technologies, DICT, Education, Childhood Education, Basic Education, Elementary School, Pandemic.

Resumen: Las Tecnologías Digitales de Información y Comunicación - TDIC son de gran relevancia en el escenario actual, especialmente en el escenario actual, ya que se observa la importancia y necesidad de la inserción de estas tecnologías en la rutina diaria de las escuelas en el proceso enseñando y aprendiendo. Sin embargo, un tema relacionado con la salud global, el nuevo coronavirus, impuso el uso de estas herramientas de forma abrupta y con poca planificación. Estudiantes de toda la educación básica, como profesores, coordinadores, gestores y todo el equipo pedagógico, de repente necesitaron familiarizarse con el uso de las plataformas digitales de aprendizaje y sus herramientas. Teniendo en cuenta estas afirmaciones, surgieron las siguientes preguntas: Ante la situación educativa que impone la pandemia, ¿el modelo educativo (online) podrá abarcar a la mayoría de los niños en Educación Infantil, especialmente a los preescolares (4 y 5 años)? y Primaria I $\left(1^{\circ}\right.$ a $5^{\circ}$ grado), especialmente los de instituciones públicas y menos favorecidas? ¿Hubo calidad en el proceso de enseñanza y aprendizaje con este nuevo modelo de educación? Por tanto, este artículo tiene como base investigación bibliográfica con enfoque cualitativo. Los datos se recolectaron de lecturas de trabajos trabajos publicados, artículos científicos disponibles en internet, congresos y conferencias virtuales.

Palabras clave: Tecnologías Digitales de Información y Comunicación, Pandemia, Educación, Educación Infantil, Preescolares, Primaria.

\title{
INTRODUÇÃO
}

RBPPD/BRJPD | Vol. 2 | n. 4 | p. 95 -117, 2020. 
Os paradigmas educacionais que envolvem as Tecnologias Digitais de Informação e Comunicação - TDIC são de grande relevância, especialmente diante do cenário atual, pois observa-se a importância e necessidade da inserção dessas tecnologias no dia a dia das escolas no processo de ensino e aprendizagem. Porém, uma questão relacionada à saúde mundial, o novo coronavírus, impôs o uso dessas ferramentas de maneira abrupta e com pouco planejamento, trazendo à tona a urgente qualificação profissional nesta área, enquadrando professores e alunos à nova realidade educacional, devido ao distanciamento social e ao fechamento das escolas.

\begin{abstract}
Os professores precisam reaprender a ensinar. Não basta mais falar e falar para convencer, mas explicar para os alunos o que estão vendo e ouvindo. Para isso é necessário utilizar as ferramentas que barateiam o acesso aos sentidos, visão e audição, que são os computadores e celulares. Os celulares e tablets permitem inclusive a incorporação do tato. Isso não significa que lápis e cadernos estão obsoletos. Machados não se tornaram obsoletos por causa da serra elétrica. Apenas são usados em situações mais específicas. O futuro próximo sugere um novo ajuste, iniciado por uma ferramenta virtual de sistema, que cada dia mais empurra as pessoas para uma mesma percepção sobre a realidade (MORAES, 2020, n.p).
\end{abstract}

Assim, estudantes de toda a educação básica, bem como professores, coordenadores, gestores e toda a equipe pedagógica, precisaram, repentinamente, familiarizar-se com o uso das plataformas digitais de aprendizagem e suas ferramentas. Com isso, evidenciou-se que apesar da enorme relevância, indiscutível, das relações sociais para o desenvolvimento intelectual, moral e social do ser humano, é possível compartilhar conhecimento virtualmente, transferindo a aprendizagem solitária e individual a uma aprendizagem cooperativa.

É certo que com a nova educação imposta pela pandemia, e consequente

RBPPD/BRJPD | Vol. 2 | n. 4 | p. 95 -117, 2020. 
distanciamento social, a quebra do paradigma relacionado às ferramentas digitais e à educação a distância, precisou ser aceita, com todas as dificuldades vivenciadas por docentes, alunos e famílias.

Levando tais afirmações em consideração, surgiram os seguintes questionamentos: Frente a conjuntura educacional imposta pela pandemia, será que o modelo de educação (online) conseguiu englobar a maioria das crianças da Educação Infantil, principalmente as crianças da pré-escola (4 e 5 anos) e do Ensino Fundamental I ( $1^{\circ}$ ao $5^{\circ}$ ano), em especial as advindas de instituições públicas e menos favorecidas? Será que houve qualidade no processo de ensino e aprendizagem com esse novo modelo de educação?

A crise, mencionada constantemente pelas redes de informação e pela sociedade, não surgiu com a pandemia. Seja na saúde, economia, política, social ou educacional, a crise, antes desse período, era presente, e apenas se intensificou diante desse cenário. Nesse artigo, a discussão será sobre a Educação Infantil e Ensino Fundamental I, especificamente a introdução acelerada das TDIC nessas etapas de ensino formal, levando em consideração e acreditando no pressuposto de que a educação pode ser entendida como a base de tudo, auxiliando no enfrentamento de crises e problemas, com sabedoria e coerência.

Portanto, este artigo é resultado de uma pesquisa bibliográfica de abordagem qualitativa. Esse procedimento técnico visa estudar os materiais científicos a partir de leituras de obras publicadas e artigos científicos disponíveis na internet. Realizou-se uma seleção minuciosa dos autores que embasariam os argumentos, bem como procurou-se periódicos dentro da perspectiva atual. A participação em congressos e palestras virtuais foi considerada também de extrema importância, pois tais eventos apontam e discutem temas recentes,

RBPPD/BRJPD | Vol. 2 | n. 4 | p. 95 -117, 2020. 
contribuindo significativamente com a fundamentação teórica. Assim, buscou-se analisar os dados a partir das leituras realizadas de obras condizentes com o tema, registrando as informações mais relevantes desses periódicos, bem como das palestras e congressos, organizando-os em sequência lógica e coerente.

\section{O USO DAS TDIC NA EDUCAÇÃO}

É certo que nos últimos anos, especialmente após a Lei de Diretrizes e Bases da Educação Nacional - LDB 9.394/96 e mais recentemente com a implementação da Base Nacional Comum Curricular - BNCC, fala-se na importância de incluir as TDIC na sala de aula, pois além de hoje os alunos nascerem inseridos nesse contexto digital, as TDIC ajudam a promover aprendizagens significativas, alinhadas à realidade dos alunos, despertando o interesse (TECNOLOGIAS..., 2020), e isso não pode ser ignorado pela instituição escolar. A comunicação dialógica se faz presente, e entre professor e aluno torna-se ainda mais evidente, quando o educador utiliza essas tecnologias, uma vez que, ao disponibilizar os materiais previamente para os alunos, estes já se familiarizam com o conteúdo e, ao participarem da aula, contribuem com a aprendizagem dos colegas. Dessa forma, conforme Kenski (2015, p. 89).

É preciso que ele possa estar preparado para interagir e dialogar - junto com seus alunos $[\ldots]$. Em um mundo que muda rapidamente o professor deve auxiliar seus alunos a analisar criticamente as situações complexas e inesperadas informadas pelas mídias; a desenvolver suas criatividades; a utilizar outros tipos de "racionalidades": a imaginação criadora, a sensibilidade táctil, visual e auditiva, entre outras. [...].

Porém, os professores precisam estar preparados para essa inserção, buscando na

RBPPD/BRJPD | Vol. 2 | n. 4 | p. 95 -117, 2020. 
formação continuada a alfabetização e o letramento digital, possibilitando a inclusão dessas tecnologias de maneira pedagógica e com intencionalidade.

O novo cenário educacional, imposto pela pandemia do coronavírus, não ofertou tempo para que esse aperfeiçoamento se desse de maneira detalhada, com planejamento adequado e objetivos claros, priorizando o aluno, centro do processo de ensino e aprendizagem. As instituições de ensino, secretarias de educação, coordenação, enfim, precisaram correr contra o tempo e continuar oferecendo educação formal a milhares de estudantes do ensino básico, na situação da pandemia.

A partir de então, problematiza-se a qualidade dessa nova educação, bem como se essa modalidade de ensino é efetiva, pois Borges et al. acreditam que o ensino presencial na educação básica seja primordial. Só ele é capaz de garantir essa qualidade a todos os estudantes, e só ele possibilita o atendimento especializado aos alunos com necessidades especiais, a merenda ofertada a muitas crianças em situação de vulnerabilidade social, isso sem contar a interação face a face, proximidade e troca de experiências vivas (BORGES et al., 2020).

Além disso, a grande maioria das escolas públicas não têm recursos para oferecer educação a distância. É importante frisar também que, um número significativo de estudantes da educação infantil e ensino fundamental I, faz parte de um grupo vulnerável socialmente, que não dispõe de acesso à internet, bem como de equipamentos tecnológicos que possam dar suporte ao processo de ensino e aprendizagem (SANTOS, 2020).

Porém, mesmo na incerteza se essa modalidade englobaria todos os alunos, foi a

RBPPD/BRJPD | Vol. 2 | n. 4 | p. 95 -117, 2020. 
opção escolhida diante da pandemia, restando à educação remota a reinvenção de momentos também de interações significativas, aprendizado constante e inovadores dentro desse contexto.

Partindo desse pressuposto, ao inserir as TDIC na educação, o professor-mediador, possibilita aos alunos que tiverem acesso, uma gama diversificada de tecnologias, oportunizando sua desmistificação e democratização (D’AVILA; MAISSIAT, 2019). Para isso, conforme já mencionado, é importante promover letramento digital aos professores, uma vez que a formação adequada possibilita a implementação das metodologias ativas em sala de aula.

Para Moran (2018 p. 41), “metodologias ativas são estratégias de ensino centradas na participação efetiva dos estudantes na construção do processo de aprendizagem, de forma flexível, interligada e híbrida”. Essas metodologias baseiam-se no ensino híbrido, aprendizagem baseada em projetos, sala de aula invertida, STEAM e cultura Maker. (BACICH; MORAN, 2018).

Nesse sentido, a competência geral 5 da BNCC - Base Nacional Comum Curricular, contempla o desenvolvimento de habilidades e competências, com o uso responsável e crítico das TDIC a saber:

Compreender, utilizar e criar tecnologias digitais de informação e comunicação de forma crítica, significativa, reflexiva e ética nas diversas práticas sociais (incluindo as escolares) para se comunicar, acessar e disseminar informações, produzir conhecimentos, resolver problemas e exercer protagonismo e autoria na vida pessoal e coletiva. (BNCC, 2017 p. 9).

Aliado a esse contexto, Santos (2020), afirma que as tecnologias ganham espaço nas

RBPPD/BRJPD | Vol. 2 | n. 4 | p. 95 -117, 2020. 
salas de aula virtuais, ressignificando atividades e projetos pedagógicos. Porém, o uso das TDIC, como meio para promover a educação, traz à tona a exclusão digital presente na sociedade. Conforme dados do IBGE - Instituto Brasileiro de Geografia e Estatística, em 2018 a internet no território brasileiro chegou somente a oito em cada dez residências, sendo utilizada em 79,1\% dos domicílios brasileiros. "Um crescimento considerável, se comparado ao ano de 2017 (74,9\%). A maior parte desses domicílios fica concentrada nas áreas urbanas das Grandes Regiões do país.” (IBGE Educa, 2018)

Apesar do crescimento significativo de acesso à internet no lar dos brasileiros, nota-se ainda um número considerável de pessoas, cerca de $20,9 \%$ que não possuem este acesso. A pesquisa mostrou que entre os principais motivos que dificultam a acessibilidade está a falta de interesse, com $34,7 \%$, alto custo do serviço, $25,4 \%$, e desinformação sobre como usar, com 24,3\%. (IBGE Educa, 2018).

Outra pesquisa, divulgada em junho de 2020 pela TIC Kids Online Brasil 2019, afirma que "4,8 milhões de crianças e adolescentes entre 9 e 17 anos, no Brasil, vivem em domicílios sem acesso à internet — o que corresponde a 18\% dessa população.” (STEVANIN, 2020 p. $10)$.

Assim, o ensino remoto - nota-se que ensino a distância e ensino remoto são diferentes, pois o primeiro refere-se a educação em tempos e lugares diversos e exige planejamento, enquanto o segundo abrange uma medida necessária aprovada pelo MEC, devido a pandemia da Covid-19, - foi liberado pelo Ministério da Educação - MEC, mesmo com muitas crianças e adolescentes não tendo acesso às tecnologias digitais. Todavia, se essa não fosse a opção para manter a educação no país, é possível que ainda um número maior de

RBPPD/BRJPD | Vol. 2 | n. 4 | p. 95 -117, 2020. 
estudantes abandonariam seus estudos. (BORGES et al., 2020).

\section{CENÁRIOS DA EDUCAÇÃO BÁSICA}

A educação básica nacional visa a mudanças, significativas, de paradigmas no processo de aprendizagem que contemplem inúmeras habilidades e competências a serem desenvolvidas pelos estudantes. Essas mudanças, normalmente acontecem de maneira gradual, pois exigem uma ruptura desses paradigmas em todos os envolvidos. "Os alunos não são tábulas rasas. Eles têm vivências e muita bagagem. Isso precisa ser levado em consideração para promover aulas criativas que favoreçam uma aprendizagem rica e contextualizada.” (Informação verbal) ${ }^{1}$. Assim, os professores precisam substituir a ideia de que o estudante será moldado conforme suas crenças profissionais, e enxergá-lo como um ser social, que ao chegar à escola, traz consigo inúmeras experiências.

Dessa forma, migra para uma educação 4.0, na qual muitos estudiosos têm defendido. Porém, a educação 1.0 - educação tradicionalista, na que perguntas e respostas são definidas por especialistas -, 2.0 - quando os participantes definem as perguntas, mas os especialistas definem as respostas -, e 3.0 - em conjunto, professores, alunos e especialistas, definem as perguntas e as respostas -, estão ainda muito presentes nas salas de aula. (Informação verbal $)^{2}$.

$1 \quad$ Fala da prof ${ }^{\mathrm{D}}$ Taise Telles proferida na palestra "Metodologia analítica como suporte a aprendizagem adaptativa e personalizada: as trilhas de aprendizagem", em Congresso Online das Tecnologias da Educação a Distância - CONTEAD, em set. 2020.

2 Fala da prof $^{0}$ Daniela Gutierrez proferida na palestra " Facilitação como impulsionadora da educação 4.0", em Congresso Internacional ABED de Educação a Distância - Ed. Virtual, em set. 2020.

RBPPD/BRJPD | Vol. 2 | n. 4 | p. 95 -117, 2020. 
Para entender melhor, Gutierrez conceitua a educação 4.0 como sendo aquela em que o educando tem um papel ativo na sua aprendizagem, é protagonista, decidindo o quê, onde e como aprender. Nesse caso, o professor torna-se um facilitador da aprendizagem, um mediador, tanto na modalidade presencial quanto na modalidade a distância. O trabalho em grupo está muito mais presente, possibilitando trocas de experiências. Pode-se falar, assim, em metodologias ativas presentes no contexto da sala de aula. (Informação verbal) ${ }^{3}$.

Nesse contexto, com as transformações das sociedades, oriundas do avanço das tecnologias e a exigência de um mercado com profissionais competentes, a educação 4.0 parte do pressuposto da necessidade de formar cidadãos capazes de resolver problemas, com habilidades em várias áreas do conhecimento, empáticos, resilientes, com espírito crítico e investigativo.

Assim, a educação 4.0, segundo Andrade (2018), tem como principal característica a inclusão das tecnologias em sala de aula, oportunizando a estimulação e a troca de conhecimento. Porém, não basta inserir essas tecnologias, mas sim saber utilizar essas ferramentas de maneira colaborativa e lúdica. A escola deveria buscar uma educação muito mais centrada em atividades, e menos em conteúdo, assim como a proposta da sala de aula invertida prevê; promover entre os estudantes muito mais uma aprendizagem constante (lifelong learning) do que exigir que estudem para tirar uma boa nota na prova, bem como deslocar a centralidade do processo de ensino e aprendizagem ao aluno, e não mais na figura

Fala da prof ${ }^{\circ}$ Daniela Gutierrez proferida na palestra “ Facilitação como impulsionadora da educação 4.0”, em Congresso Internacional ABED de Educação a Distância - Ed. Virtual, em set. 2020.

RBPPD/BRJPD | Vol. 2 | n. 4 | p. 95 -117, 2020. 
do professor (Informação verbal) ${ }^{4}$.

Nesse contexto, evidencia-se o atual cenário educativo, em que a educação precisou inserir o uso de algumas TDIC à oferta do ensino de maneira geral, na incerteza da garantia, desses recursos utilizados, promoverem a aprendizagem. Assim, conforme já mencionado, muitas instituições de educação básica optaram por oferecer aulas online, síncronas e assíncronas, utilizando a internet como recurso essencial para que o ensino continuasse, bem como diversas ferramentas de interação virtual.

Complementando as considerações acima, Moreira e Schlemmer (2020 p. 09) afirmam que nessa modalidade,

O ensino presencial físico (mesmos cursos, currículo, metodologias e práticas pedagógicas) é transposto para os meios digitais, em rede. O processo é centrado no conteúdo, que é ministrado pelo mesmo professor da aula presencial física. Embora haja um distanciamento geográfico, privilegia-se o compartilhamento de um mesmo tempo, ou seja, a aula ocorre num tempo síncrono, seguindo princípios do ensino presencial. A comunicação é predominantemente bidirecional, do tipo um para muitos, no qual o professor protagoniza vídeo-aula ou realiza uma aula expositiva por meio de sistemas de webconferência. Dessa forma, a presença física do professor e do aluno no espaço da sala de aula geográfica são substituídas por uma presença digital numa sala de aula digital.

Esse cenário mostrou uma série de incertezas e configurou-se da seguinte forma, segundo Barros: $\mathrm{O}$ presencial precisou ceder lugar ao online, mas sem adequar as metodologias à nova realidade, muito pelo contrário, houve apenas uma transposição do ensino presencial para o online. Além disso, muitas dificuldades surgiram na compreensão

4 Fala do prof ${ }^{\circ}$ Paulo Tomazinho proferida na palestra "Aprendizagem Combinada: desafios e oportunidades", em Congresso Internacional ABED de Educação a Distância - Ed. Virtual, em set. 2020.

RBPPD/BRJPD | Vol. 2 | n. 4 | p. 95 -117, 2020. 
desse formato de comunicação, a utilização de muitas ferramentas, aplicativos e plataformas simultaneamente, sem saber qual a mais adequada, sem falar na ausência de sensibilização por parte dos professores para essa pedagogia do online. (Informação verbal) ${ }^{5}$.

Em um primeiro momento, chamou-se essa nova realidade de ensino remoto emergencial, conforme apresenta Tomazinho pois, repentinamente, as escolas precisaram buscar soluções emergentes, ou seja, sem planejamento e sem preparo dos profissionais. Em um segundo momento, passou-se a chamar de ensino remoto intencional, rapidamente planejado, adequando-se à realidade. (Informação verbal) ${ }^{6}$.

Assim, surgiu o questionamento se o ensino proposto nesse momento seria educação a distância. Para fins dessa modalidade, EaD, de acordo com o Decreto nº 9.057, de 2017, em seu Art. $1^{\text {o }}$, e que regulamenta o art. 80 da Lei $\mathrm{n}^{\mathrm{o}}$ 9.394, de 20 de dezembro de 1996, a LDB, afirma o seguinte:

[...] considera-se educação a distância a modalidade educacional na qual a mediação didático-pedagógica nos processos de ensino e aprendizagem ocorra com a utilização de meios e tecnologias de informação e comunicação, com pessoal qualificado, com políticas de acesso, com acompanhamento e avaliação compatíveis, entre outros, e desenvolva atividades educativas por estudantes e profissionais da educação que estejam em lugares e tempos diversos. (BRASIL, 2017, n.p.).

Hodges et al. (apud ARRUDA, 2020, p. 265) "afirmam que a educação remota online digital se diferencia da Educação a Distância pelo caráter emergencial que propõe usos e

5 Fala da profa. Daniela M. V. Barros proferida na palestra "Cenários para a Educação Online: tendências e perspectivas pós covid 19”, em Congresso Online das Tecnologias da Educação a Distância - CONTEAD, em set. 2020.

6 Fala do $\operatorname{prof}^{\circ}$ Paulo Tomazinho proferida na palestra "Aprendizagem Combinada: desafios e oportunidades", em Congresso Internacional ABED de Educação a Distância - Ed. Virtual, em set. 2020.

RBPPD/BRJPD | Vol. 2 | n. 4 | p. 95 -117, 2020. 
apropriações das tecnologias em circunstâncias específicas de atendimento onde outrora existia regularmente a educação presencial."

Considerando o anteriormente exposto, pressupõe-se que, somente fazer usos das TDIC não significa implantar educação a distância, pois esta envolve uma série de regulamentações, políticas de acesso, bem como avaliações compatíveis com a modalidade. Apesar de o decreto 9.057 e a LDB utilizarem a nomenclatura "educação a distância", esta refere-se ao fato de o processo de ensino e aprendizagem acontecer em tempos e espaços diversos. Algumas TDIC estão presentes por mera necessidade, com pouco ou nenhum planejamento. Acredita-se que com o passar dos meses, desde o início da suspensão das aulas presenciais, os professores e as instituições, possivelmente já dominem melhor essas tecnologias digitais, o que não significa que estas estejam engajadas na promoção das habilidades e competências que os estudantes precisam desenvolver.

Conforme Arruda (2020 p. 266),

[...] a educação remota é um princípio importante para manter o vínculo entre estudantes, professores e demais profissionais da Educação. A resposta em contrário pode representar o afastamento por muitos meses dos estudantes dos espaços escolares (físicos e virtuais), o que pode comprometer a qualidade da educação, possivelmente mais do que a implementação de iniciativas que mantenham tais vínculos, apesar das limitações que venham a conferir.

Acredita-se que a mudança de paradigmas em relação à educação a distância, ao uso de plataformas que incentivem uma educação inovadora, já esteja em andamento, pois a educação, após a pandemia, possivelmente tenderá ao ensino híbrido, ao uso de recursos tecnológicos, bem como de situações engajadoras que fomentem e incentivem práticas de cidadania. Além disso, a promoção de uma aprendizagem significativa aos estudantes, deve

RBPPD/BRJPD | Vol. 2 | n. 4 | p. 95 -117, 2020. 
gerar, ainda num futuro próximo, conforme expõe Barros,

[...] cidadania digital, realismo, virtualização da realidade, soluções de maior escala para serem utilizadas de forma contextualizada e significativa, superação de paradigmas (quebra, aceitação, resiliência e colaboração, processos de solidariedade partilhada e intencional), aperfeiçoamento e desenvolvimento das competências da comunicação (multi), e aplicação direta de conceitos mencionados anteriormente por visionários da educação que estavam no campo das ideias e que agora são transpostos à realidade, como por exemplo "Aprender a Aprender". (Informação verbal $)^{7}$.

Com o retorno das aulas presenciais em todo o país, espera-se que esse momento desperte, nos responsáveis pela educação, a conscientização de que as TDIC devam fazer parte do contexto educativo e oportunizar aprendizagem significativa, crítica e responsável aos estudantes.

\subsection{Na Educação Infantil}

A educação infantil, primeira etapa da educação básica, conforme a Lei de Diretrizes e Bases da Educação Nacional - LDB 9.394/96, foi fortemente impactada pela pandemia. As crianças de 0 a 3 anos frequentam as chamadas "creches", e apesar dessa faixa etária não ter a obrigatoriedade da frequência, é um direito da criança ser atendida com qualidade, possibilitando seu pleno desenvolvimento, conforme consta no artigo 29 da lei maior da educação nacional, a LDB, “A educação infantil, primeira etapa da educação básica, tem como finalidade o desenvolvimento integral da criança de até 5 (cinco) anos, em seus aspectos físico, psicológico, intelectual e social, complementando a ação da família e da comunidade.” (BRASIL, 1996, n.p.).

7 Fala da profa. Daniela M. V. Barros proferida na palestra "Cenários para a Educação Online: tendências e perspectivas pós covid 19”, em Congresso Online das Tecnologias da Educação a Distância - CONTEAD, em set. 2020.

RBPPD/BRJPD | Vol. 2 | n. 4 | p. 95 -117, 2020. 
De acordo com as DCNEI - Diretrizes Curriculares Nacionais da Educação Infantil (DCNEI, Resolução CNE/CEB n ${ }^{\circ}$ 5/2009), em seu Artigo 9º as interações e as brincadeiras são os eixos norteadores das práticas pedagógicas, oportunizando às crianças diversas experiências e interações com outras crianças e com os adultos que ali se encontram. Além disso, as famílias precisam desse atendimento para que possam exercer suas funções profissionais.

Para as crianças de 4 e 5 anos, além do direito à educação assegurado desde a Constituição Federal de 1988, a partir de 2009 essa faixa etária, que contempla o pré-escolar, tornou-se com frequência obrigatória, conforme o artigo $4^{\circ}$ : “O dever do Estado com educação escolar pública será efetivado mediante a garantia de: I - educação básica obrigatória e gratuita dos 4 (quatro) aos 17 (dezessete) anos de idade.” (BRASIL, 1996, n.p.).

Diante da pandemia surgiu a preocupação em como ofertar educação a essas crianças, especialmente as que compõem o ensino obrigatório, pois elas não possuem domínio e autonomia para manipularem as ferramentas digitais, utilizadas como meio para promover a educação formal, precisando de auxílio e disponibilidade dos responsáveis. Isso sem contar que as atividades propostas pelos professores, antes realizadas na instituição, agora necessitam, mais do que nunca, da parceria dos pais para sua execução.

Há também que se considerar que as DCNEI definem direitos de aprendizagem e desenvolvimento às crianças na Educação Infantil. Direitos esses de convivência, brincadeiras, participação, exploração, livre expressão e conhecimento. Assim, uma vez que o atendimento presencial foi suspenso, esses direitos ficaram comprometidos.

\footnotetext{
RBPPD/BRJPD | Vol. 2 | n. 4 | p. 95 -117, 2020.
} 
Percebe-se que nem todas as famílias têm consciência da importância da educação infantil para o desenvolvimento das crianças, pois veem essa oferta como assistencialista. Isso explica a maior dificuldade das instituições e dos educadores em envolver essas famílias na colaboração com as atividades escolares, da necessária devolutiva dessas atividades para que o professor acompanhe o crescimento e evolução de seus alunos, e a proposta de atividades que supram as necessidades de desenvolvimento dessas crianças, bem como a mínima garantia dos direitos de aprendizagem e convivência, conforme propõe a Base Nacional Comum Curricular - BNCC (2017).

\subsection{No Ensino Fundamental I}

Nas primeiras séries dos anos iniciais, a educação remota emergencial também levantou inúmeras preocupações. Considerando que do $1^{\circ}$ ao $3^{\circ}$ ano a alfabetização está em construção, acredita-se que seria de suma importância que a aprendizagem ocorresse em ambientes presenciais, com a figura do professor, interlocutor e mediador desse processo. Assim, Coutinho aborda essa problemática como uma "imposição para a família da execução do processo de alfabetização, que não lhe pertence nem lhe cabe e que, é feito, frequentemente, de modo improvisado, muitas vezes, sem o acompanhamento dos profissionais da educação" (COUTINHO et al., 2020 apud LEÃO et al., 2020 p. 21). As chances de ocorrer um fracasso nesse processo, são consideráveis, pois a maioria das famílias responsabilizadas em dar suporte às crianças, não tem nenhuma preparação.

Tratando-se de legislação, e dentro desse cenário, o Decreto $n^{0}$ 9.057, de 2017, prevê a

RBPPD/BRJPD | Vol. 2 | n. 4 | p. $95-117,2020$. 
educação a distância para o ensino fundamental em situações emergenciais, art. $8^{\circ}$ "I - ensino fundamental, nos termos do parágrafo $\S 4^{\circ}$ do art. 32 da Lei $n^{\circ} 9.394$, de 20 de dezembro de 1996 (§ $4^{\circ} \mathrm{O}$ ensino fundamental será presencial, sendo o ensino a distância utilizado como complementação da aprendizagem ou em situações emergenciais)" (BRASIL, 2017, n.p.). Assim, a solução encontrada, neste momento de pandemia e de distanciamento social, foi oferecer educação utilizando meios digitais.

No Ensino Fundamental I, nem todos os alunos estão familiarizados com a tecnologia, especialmente, os alunos da rede pública de ensino, que acabam tendo menos acesso a essas ferramentas digitais. Conforme mencionado anteriormente, 4,8 milhões de estudantes entre 9 e 17 anos não têm acesso à internet (STEVANIN, 2020). Tornar esse processo de ensino e aprendizagem ativo foi desafiador, tanto para os professores e instituições, quanto para as crianças e suas famílias.

Apenas como ilustração das dificuldades encontradas, a avaliação durante o período de aulas remotas também precisou ser adaptada, e para que houvesse sucesso nesse processo, os professores precisaram incentivar os estudantes a participarem das aulas online, a realizarem as atividades propostas e a tirarem suas dúvidas sempre que necessário. $\mathrm{O}$ professor também precisa dar um feedback, pois, caso contrário, o aluno pode perder o interesse em executar os exercícios e participar das aulas.

Silva (2020) acredita que alguns modelos de avaliação ajudarão nesse processo, como, por exemplo, as rubricas de aprendizagem: tabela dos objetivos de aprendizagem - o que o aluno atingiu; pequenos questionários: formulários ou quizzes; dividir as entregas das atividades em etapas menores: dessa maneira, os alunos administram melhor o tempo,

RBPPD/BRJPD | Vol. 2 | n. 4 | p. 95 -117, 2020. 
diminuindo a ansiedade; autoavaliação: é muito importante ouvir o aluno, suas dificuldades, preferências; e os portfólios também são ótimos recursos de avaliação (Informação verbal) ${ }^{8}$.

Sendo assim, ao fim de todo esse cenário, ou seja, quando as aulas presenciais forem retomadas em todas as regiões do país, - em algumas o retorno gradual já estava acontecendo, - os professores precisarão verificar se uma série de habilidades e competências se concretizaram na aprendizagem desses alunos. Além disso, e para fins de garantia de qualidade, acredita-se que o mais sensato seria estimular e promover, concretamente, através de metodologias ativas e cooperação, as aprendizagens necessárias para cada etapa da educação.

\section{CONSIDERAÇÕES FINAIS}

Percebe-se que, somado à pandemia do novo coronavírus, os professores da educação básica, especialmente os interlocutores da educação infantil e ensino fundamental I, precisam buscar na formação continuada a alfabetização e o letramento digital, para a inserção das TDIC em suas aulas. Ouve-se falar na resistência e preconceito, de alguns profissionais da educação, atrelados a oferta de educação a distância, por meio das tecnologias digitais, muitas vezes, por não estarem familiarizados com a metodologia.

Dessa forma, Litto (2020, s.p.) afirma que “o preconceito é mais uma manifestação da falha ao ensinar adequadamente o pensamento crítico em nossas escolas”. Esse mesmo

\footnotetext{
$8 \quad$ Fala da prof ${ }^{o}$. Ângela T. F. Silva, proferida na palestra "Avaliação em aulas remotas"., em Congresso
} Online das Tecnologias da Educação a Distância - CONTEAD, em set. de 2020.

RBPPD/BRJPD | Vol. 2 | n. 4 | p. 95 -117, 2020. 
preconceito está infundido, muitas vezes, nas experiências que os próprios docentes tiveram durante sua formação. Acredita-se que a tendência é que aquele profissional que se formou na graduação a distância, tenha mais facilidade em aceitar as aulas remotas, ao contrário daqueles que sempre estudaram presencialmente.

Porém, acredita-se que o uso por si só das TDIC não melhora a qualidade da educação, devido, principalmente, a transposição das aulas expositivas e bidirecionais presentes no ensino presencial, às aulas síncronas, tampouco, diante desse cenário, consegue favorecer todos os alunos. Além disso, há quem acredite que somente a educação presencial é capaz de suprir todas as necessidades dos estudantes e garantir essa qualidade, considerando um acompanhamento contínuo do processo de ensino e aprendizagem por parte do docente, e a inclusão de todos os alunos à educação.

Levando em conta a necessária permanência da oferta da educação formal, o ensino remoto, e o uso das TDIC, foram algumas das soluções encontradas para que a educação não descontinuasse, caso contrário, muitos estudantes desistiriam da escola e futuramente arcariam com as consequências dessa decisão.

$\mathrm{O}$ acesso às aulas remotas e a necessidade de acesso às aulas online, mostraram a grande desigualdade social que ainda permeia o país. Os números demonstraram a grande porcentagem de estudantes que não estão conectados à rede, e que, possivelmente, precisarão correr atrás do prejuízo futuramente. O Brasil precisa investir em maneiras de facilitar o acesso dos estudantes às tecnologias digitais de informação e comunicação, assim como, à internet.

RBPPD/BRJPD | Vol. 2 | n. 4 | p. $95-117,2020$. 
Há de se considerar que as mudanças de paradigmas na educação são essenciais para acompanhar o ritmo acelerado da evolução da sociedade em todos os cenários. Assim, a educação de hoje precisa estar à frente, oportunizando momentos de interação e diálogo, guiando os alunos na construção de habilidades e competências necessárias para a vida e o novo mundo que se apresenta.

O professor precisa mudar seu papel, pois já não bastam as aulas expositivas e monólogas. O aluno deve ser autor de sua aprendizagem, participando ativamente. Mas, infelizmente, o que se observou foi uma transposição das aulas presenciais na nova modalidade online. Consequentemente, alunos desinteressados, cansados e com baixo nível de aprendizagem.

O fechamento das instituições de educação infantil também trouxe incertezas quanto à garantia dos direitos de brincar, conviver com outras crianças e adultos, de participar, explorar, de expressar-se e conhecer-se, além da dificuldade em aproximar as famílias da educação de seus filhos, uma vez que, mais do que nunca, a escola precisou se amparar nessas famílias para dar continuidade ao processo de desenvolvimento pleno dessas crianças.

No ensino fundamental I, principalmente aos alunos em processo de alfabetização, a qualidade da educação pode ter ficado comprometida. Os professores precisarão retomar os conteúdos e a mediação adequada dessa aprendizagem, apresentando metodologias inovadoras e que tragam resultados desejados.

Em suma, quando a pandemia passar, a educação será dividida em pré e pós-covid-19. E espera-se que o modelo educacional pós-covid viabilize um ensino muito mais voltado para

RBPPD/BRJPD | Vol. 2 | n. 4 | p. 95 -117, 2020. 
entender como o aluno aprende, e menos para como ensinar. Mais interatividade, aprendizagem cooperativa e menos aulas expositivas centradas no conteúdo. Mais atenção ao estudante e ao profissional da educação. Além disso, que esse início acelerado da inserção das TDIC impulsione uma educação preocupada em oportunizar experiências que desenvolvam competências e habilidades nos estudantes, essenciais para um futuro próximo.

\section{REFERENCIAS}

ANDRADE, Karen. Guia definitivo da educação 4.0. São Paulo: Planeta educação. Disponível em: http://www.plannetaeducacao.com.br/portal/arquivo/editor/file/ebook-educacao4.0-planneta.p df. Acesso em: 21 set. 2020.

ARRUDA, E. P. Educação Remota Emergencial: elementos para políticas públicas na educação brasileira em tempos de Covid-19. EmRede - Revista de Educação a Distância, v. 7, n. 1, p. 257-275, maio 2020. Disponível em: https://www.aunirede.org.br/revista/index.php/emrede/\%20article/view/621. Acesso em: 17 set. 2020 .

BACICH, Lilian; MORAN, José (org.). Metodologias ativas para uma educação inovadora: uma abordagem teórico prática. Porto Alegre: Penso, 2018.

BORGES, E. M. et al. Em defesa das tecnologias da informação e comunicação na educação básica: diálogos em tempos de pandemia. Revista Plurais, Salvador, v. 5, n. 1 p. 146-149, jan/abr. 2020. Disponível em: https://www.researchgate.net/publication/342979258_EM_DEFESA_DAS_TECNOLOGIAS _DE_INFORMACAO_E_COMUNICACAO_NA_EDUCACAO_BĀSICĀ_dialogos_em_te mpos_de_pandemia. Acesso em: 17 set. 2020.

BRASIL. [Constituição (1988)]. Constituição da República Federativa do Brasil de 1988. Brasília, DF: Presidência da República, [2016]. Disponível em: http://www.planalto.gov.br/ccivil_03/constituicao/constituicao.htm. Acesso em: 15 dez. 2020.

BRASIL. Decreto $\mathbf{n}^{0}$ 9.057, de 25 de maio de 2017. Regulamenta o art. 80 da Lei ${ }^{0}$ 9.394, de 20 de dezembro de 1996 . Estabelece as diretrizes e bases da educação nacional. Disponível em:

RBPPD/BRJPD | Vol. 2 | n. 4 | p. 95 -117, 2020. 
http://www.planalto.gov.br/ccivil_03/_Ato2015-2018/2017/Decreto/D9057.htm. Acesso em: 17 set. 2020.

BRASIL. Diretrizes Curriculares Nacionais da Educação Infantil - DCNEI. Resolução CNE/CEB no 5/2009. Disponível em: http://portal.mec.gov.br/dmdocuments/rceb005_09.pdf. Acesso em: 18 set. 2020.

BRASIL. Lei de Diretrizes e Bases da Educação Nacional, LDB. 9.394/1996. BRASIL.

Disponível em: http://www.planalto.gov.br/ccivil_03/leis/19394.htm. Acesso em: 17 set. 2020.

BRASIL. Ministério da Educação. Secretaria da Educação Básica. Base Nacional Comum Curricular - BNCC Brasília, DF, 2020. Disponível em:

http://basenacionalcomum.mec.gov.br/images/BNCC_EI_EF_110518_versaofinal_site.pdf. Acesso em: 18 set. 2020.

D’AVILA, Fernanda V. S. ; MAISSIATI, Jaqueline. Tecnologias digitais e educação infantil: formação continuada de professores para uso dos instrumentos digitais no ato educativo. Vitória, ES: Instituto Federal de Educação, Ciência e Tecnologia do Espírito Santo, 2019. Disponível em:

https://educapes.capes.gov.br/bitstream/capes/559891/2/Fernanda\%20Sofiatti_Produto\%20Ed ucacional_Humanidades.pdf. Acesso em: 20 set. 2020.

IBGE Educa. Uso de Internet, televisão e celular no Brasil. Disponível em:

https://educa.ibge.gov.br/criancas/brasil/2697-ie-ibge-educa/jovens/materias-especiais/20787uso-de-internet-televisao-e-celular-no-brasil.html. Acesso em: 18 set. 2020.

KENSKI, Vani M. Tecnologias e ensino presencial e a distância. Campinas: SP: Papirus, 2015 - Prática Pedagógica.

LEÃO, M. L. P.; OLIVEIRA, M. T. D.; LEÃO, S. O. P. Alfabetização na pandemia: políticas públicas do estado de Minas Gerais, Brasil, direcionadas à educação nos anos iniciais do ensino fundamental no período de isolamento social. Justitia Liber, v. 2, n. 2, p. 18-22, 2020. Disponível em:

http://www.cognitionis.inf.br/index.php/civicae/article/view/CBPC2674-6646.2020.002.0004/ 54. Acesso em: 18 set. 2020.

LITTO, Fredric M. Questões polêmicas e os novos termos para descrever a educação a distância. Disponível em:

http://www.abed.org.br/site/pt/midiateca/textos_ead/1831/2020/08/questoes_polemicas_e_no vos_termos_para_descrever_a_educacao_a_distancia. Acesso em: 14 dez. 2020.

MORAES, Renato Bulcão de. O novo paradigma da educação. Disponível em:

RBPPD/BRJPD | Vol. 2 | n. 4 | p. 95 -117, 2020. 
http://www.abed.org.br/site/pt/midiateca/textos_ead/1820/2020/08/o_novo_paradigma_da_ed ucacao. Acesso em: 21 set. 2020.

MORAN, José. Metodologias ativas: uma aprendizagem profunda. In: BACICH, Lilian; MORAN, José (org.). Metodologias ativas para uma educação inovadora: uma abordagem teórico prática. Porto Alegre: Penso, 2018. p. 34-76.

MOREIRA, António José.; SCHLEMMER, Eliane. Por um novo conceito e paradigma de educação digital onlife. Revista UFG, Goiás, v. 20(26), p. 2-35, março, 2020. Disponível em: https://www.revistas.ufg.br/revistaufg/article/view/63438/34772. Acesso em: 14 dez. 2020.

SANTOS, Guilherme M. T. dos. Tecnologías digitales frente al escenario del covid-19: (in)efectividad del derecho educativo brasileño?. Brazilian Journal of Policy and Development - ISSN: 2675-102X, v. 2, n. 3, p. 35-54, 28 set. 2020. Disponível em: https://www.brjpd.com.br/brjpd/article/view/53/31. Acesso em: 21 dez. 2020. DOI: $\underline{10.29327 / 210816.2 .3-2}$

STEVANIM, Luiz Felipe. Exclusão nada remota: desigualdades sociais e digitais dificultam a garantia do direito à educação na pandemia. Disponível em:

https://www.arca.fiocruz.br/bitstream/icict/43180/2/Exclus\%c3\%a3oNadaRemota.pdf. Acesso em: 18 set. 2020 .

TECNOLOGIAS DIGITAIS DA INFORMAÇÃO E COMUNICAÇÃO NO CONTEXTO ESCOLAR: possibilidades. Disponível em:

http://basenacionalcomum.mec.gov.br/implementacao/praticas/caderno-de-praticas/aprofunda mentos/193-tecnologias-digitais-da-informacao-e-comunicacao-no-contexto-escolar-possibili dades. Acesso em: 14 dez. 2020. 